\title{
PdNi-coated manganite nanorods as catalyst for electrooxidation of methanol in alkaline medium
}

\author{
R. Kannan · K. Karunakaran $\cdot$ S. Vasanthkumar
}

Received: 21 October 2011/Accepted: 30 November 2011/Published online: 21 December 2011

(C) The Author(s) 2011. This article is published with open access at Springerlink.com

\begin{abstract}
Palladium and Nickel (PdNi) were coated on the manganite nanorods ( $\mathrm{MN})$ by a in situ reduction method. The prepared nanocatalyst was characterized by powder X-ray diffractrogram (XRD), scanning electron microscopy with energy dispersive X-ray spectrometry (SEM-EDS) and electrochemical studies. The XRD patterns and EDS measurements confirm the formation of nanocrystalline PdNi on the surface of the MN. This nanocatalyst was tested for the electrooxidation of methanol in alkaline medium. The PdNi/MN catalyst modified electrode shows improved current response when compared with $\mathrm{Pd} / \mathrm{MN}$ and $\mathrm{Pd} / \mathrm{C}$ modified electrodes. The forward oxidation potential was shifted negative and the backward oxidation current was minimized compared with $\mathrm{Pd} / \mathrm{C}$. The electrooxidation of methanol was studied at various concentrations of $\mathrm{KOH}$ and methanol. The methanol electrooxidation exhibits highest current response for $9 \mathrm{M} \mathrm{KOH} /$ $6 \mathrm{M} \mathrm{CH}_{3} \mathrm{OH}$ solution. The presence of $\mathrm{MN}$ act as excellent support material and help in the electrocatalytic activity of PdNi.
\end{abstract}

Keywords Methanol electrooxidation .

Manganese oxide $\cdot$ Palladium · Nickel · Fuel cell

R. Kannan · K. Karunakaran

Department of Chemistry, Sona College of Technology,

Salem 636 005, India

R. Kannan · S. Vasanthkumar $(\bowtie)$

School of Nanosciences and Technology,

Karunya University, Coimbatore 641 114, India

e-mail: kumar2359@yahoo.com

\section{Introduction}

Recently, alternative sources of energy have been of intensive concern due to environmental problems and also because of the decline in the availability of fossil fuels. The direct methanol fuel cell (DMFC), as one of the potential power sources for portable electronic devices or transportation vehicles, has increasingly attracted a great deal of attention due higher energy efficiency, low emission. DMFCs are promising electrochemical power sources for mobile, stationary and portable applications, and the electrocatalytic oxidation of methanol has been studied extensively. (Bianchini and Shen 2009; Suresh kumar et al. 2008; Leger 2001).

In the field of fuel cell research much attention has been paid for the preparation of metal catalyst in the nanoscale. Up to date, most of the researches on DMFC have been done using Pt and Pt-based alloys as anode catalysts due to their high catalytic ability. However due to the limited resources of $\mathrm{Pt}$, higher adsorption of $\mathrm{CO}$ as poising agent, noneffective methanol cross over etc., nonPt-based catalysts such as Pd-based catalyst has been widely studied for the methanol oxidation reaction (MOR) (Singh et al. 2009; Qi et al. 2011; Goodenough et al. 1987, 1988; Trasatti 1981; Shibata and Motoo 1986; Xu et al. 2008). Palladium (Pd), a Pt group elements available in abundance and is of low cost when compared to $\mathrm{Pt}$, which makes it attractive for usage as electrochemical anode catalyst for DAFCs (Trasatti 1981; Shibata and Motoo 1986; Xu et al. 2008; Liu et al. 2009; Maiyalagan and Scott 2010).

The poisoning of the active site of catalyst is the major drawback in DAFC. In order to reduce this poisonous effect various methods were adopted, such as placing a metal adjacent to the catalytic metal (Goodenough et al. 1987, 1988), alloys (Qi et al. 2011) or placing the catalyst 
on a suitable support (Maiyalagan and Scott 2010; Miao et al. 2010; Zhao et al. 2010). By imparting metals such as ruthenium, gold, palladium, bismuth, lead to $\mathrm{Pt} / \mathrm{Pd}$, the poisoning of catalyst surface as well as the cost of the catalyst can be minimized (Goodenough et al. 1987, 1988; Trasatti 1981; Shibata and Motoo 1986). Similarly, Ni has also been used. The introduction of $\mathrm{Ni}$ to $\mathrm{Pd}$, an oxophilic element enhances the adsorption of $\mathrm{OH}^{-}$resulting in the oxidation of the chemisorbed intermediates effectively. Investigations in this direction have just begun. Recently, various supporting materials including carbon nanotubes (Maiyalagan and Scott 2010), carbon nanofibers (Miao et al. 2010), metal oxides (Zhao et al. 2010; Wei et al. 2011; Vracar et al. 1998) etc., have been used as supporting material for various DAFCs. Among these, metal oxides exhibits improve catalytic activity, because they readily donate oxygen atom to the catalyst, improving the catalytic activity (Zhao et al. 2010).

Transition metal oxides as supporting materials for $\mathrm{Pd}$ have also been used as catalysts for alcohol oxidation which significantly improves the electrode performance by enhancing the electrochemical activity (Xu et al. 2008; Liu et al. 2009). Recently, PdNi bimetal on various support material such as carbon $(\mathrm{PdNi} / \mathrm{C})$ (Maiyalagan and $\mathrm{Scott}$ 2010; Miao et al. 2010), Si nanowires (Zhao et al. 2010), alumina (Qi et al. 2011) $\mathrm{CeO}_{2}$ (Vracar et al. 1998) and MWCNT (Singh et al. 2009; Wei et al. 2011) for alcohol electrooxidation in alkaline media was investigated. In this work, small quantities of $\mathrm{Pd}(5$ and $10 \mathrm{wt} \%)$ was tested in the presence of $\mathrm{Ni}$ coated on $\mathrm{MN}$ which were synthesized by in situ reduction method. The prepared nanocatalyst was tested for the electrooxidation of methanol in alkaline medium. The nanocatalyst exhibits an enhanced electrocatalytic activity with higher stability.

\section{Experimental}

Palladium chloride (Sigma-Aldrich), Nickel acetate, Potassium permanganate, Hydrogen peroxide (30\% W/W), acetic acid, sodium acetate, Potassium hydroxide, and Methanol received from Merck, India. All the chemicals were of analytical grade and were used without further purification.

The MN was prepared as follows, about $100 \mathrm{ml}$ of a aqueous $\mathrm{KMnO}_{4}(0.55 \mathrm{M})$ was subjected to soniciation. Hydrogen peroxide $(10 \mathrm{ml})$ and Acetate buffer $(5 \mathrm{ml})$ mixer was added drop wise into it and the sonication was continued. After $1 \mathrm{~h}$ the colloidal solution was subjected to refluxing at $60^{\circ} \mathrm{C}$ for $24 \mathrm{~h}$. The resulting product was separated, washed and dried.

Suitable quantity of $0.5 \mathrm{~mm} \mathrm{PdCl}_{2}$ and $\mathrm{Ni}(\mathrm{ac})_{2}$ solutions were taken in $5 \mathrm{ml}$ of ethanol, so as to achieve 5:10 wt $\%$ or $10: 10 \mathrm{wt} \%$ of $\mathrm{Pd} / \mathrm{Ni}$ and $100 \mathrm{mg}$ of $\mathrm{MN}$ was added and stirred. After $1 \mathrm{~h}$ formaldehyde was added to the mixture drop wise and a reductive reaction was performed at room temperature. After $6 \mathrm{~h}$, the resulting product was filtered washed with distilled water, and then dried at $60^{\circ} \mathrm{C}$ for $6 \mathrm{~h}$. The prepare $\mathrm{MN}$ and $\mathrm{PdNi} / \mathrm{MN}$ was characterized by powder XRD (Schimadzu Lab X-6000), SEM (JEOL 6390). EDS (INSTA FET, Oxford instruments) and TEM (JEOL, JSM 2100).

The glassy carbon electrode (GC, $3 \mathrm{~mm}$ diameter) was first polished with $\mathrm{Al}_{2} \mathrm{O}_{3}$ slurry. $\mathrm{PdNi} / \mathrm{MN}$ nanocomposite was ultrasonically dispersed in $0.05 \%$ of Nafion in ethanol solution. An aliquot of the PdNi/MN nanocomposite/Nafion suspension was dropped on the surface of the GC electrode and allowed to dry. Electrochemical measurements were performed with a CHI660C electrochemical workstation ( $\mathrm{CH}$ Instruments, Austin, USA) and a conventional three electrodes cell equipped with computer controlled software. The PdNi/MN nanocatalyst modified GC electrode was the working electrode, a Pt wire served as the counter electrode and a standard calomel electrode (SCE) was the reference electrode. For comparison, Pd supported on graphite powder and their electrodes were also prepared under the same preparative conditions. All potentials have been measured and reported with respect to SCE in this report. All the measurements were performed at room temperature.

\section{Results and discussion}

Physical characterization of $\mathrm{MN}$ and $\mathrm{MN} / \mathrm{PdNi}$ nanocomposite

The powder XRD patterns of the nanotubular MN and PdNi-coated $\mathrm{MN}$ is shown in Fig. 1. The XRD peaks at $2 \theta=26$ (111), 33.9 (020) can be assigned to MN and this matches well with the JCPDS \# 41-1379. The smoothened profile of PdNi modified $\mathrm{MN}$ nanocomposite exhibits similar patterns of $\mathrm{MN}$ with peaks for $\mathrm{PdNi}$ (111) at $2 \theta=41.2^{\circ}$ and a few peaks for $\mathrm{NiO}$ and $\mathrm{Pd}$ are also seen (Qi et al. 2011). The surface morphology of the $\mathrm{MN}$ and $\mathrm{PdNi} / \mathrm{MN}$ was characterized by TEM (Fig. 1b, c). The TEM images show bundles of nanoclusters of $\mathrm{MN}$ and a isolated nanorod is shown in Fig. 2a, b. Figure 2c shows the presence of nanocrystalline PdNi on the walls (red colored circle) of MN (indicated by orange colored arrow) and the lower magnification exhibits the uniformly coated PdNi on the MN (Fig. 2d).

EDS analysis were carried out to get local information of chemical properties of catalyst. EDS analysis was carried out by microprobe analysis of various portions of the catalyst thin film. It was observed that the relative intensities of $\mathrm{Pd}$ and $\mathrm{Ni}$ on $\mathrm{MN}$ signals were almost same and no 


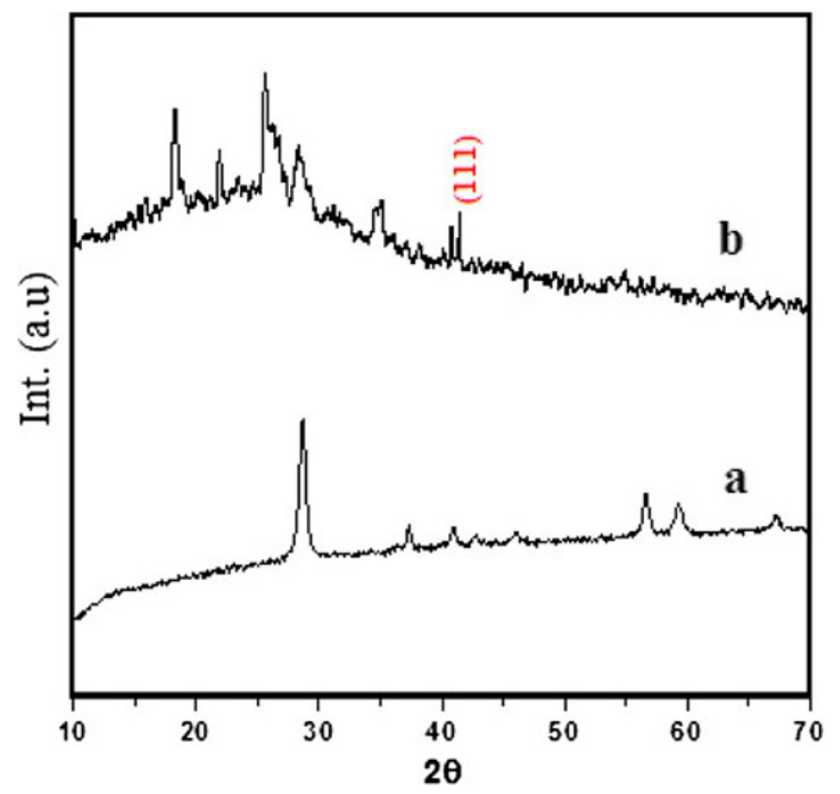

Fig. 1 X-ray diffractrogramme of the a Manganite nanorods and b PdNi-coated MN significant changes were shown in Fig. 3. EDS spectrum of $\mathrm{PdNi} / \mathrm{MN}$ catalyst, and atomic ration of composite is about 1:1.3 (Pd:Ni) on MN. The small oxygen peaks were observed, which means that some $\mathrm{Ni}$ atoms exist as $\mathrm{NiO}$. This was supported by the XRD data.

Electrooxidation of methanol at MN/PdNi modified electrode

Figure 4A shows the cyclic voltammograms of $\mathrm{Pd}$ and $\mathrm{PdNi}$ on MN support in $1 \mathrm{M} \mathrm{KOH}$ solution. In the positive sweep, the PdNi and $\mathrm{Pd}$ on MN-modified GC electrode exhibit a peak at -0.81 (Fig. 2a, b) and $-0.79 \mathrm{~V}$ (Fig. 4Aa), respectively, corresponding to the surface ad/absorbed hydrogen. The difference in the current response is due to adsorption of $\mathrm{OH}^{-}$by the $\mathrm{Ni}$ in the catalyst. The peaks at $\mathrm{E}$ $>-0.2 \mathrm{~V}$ correspond to the formation of mono Pd oxide layer. The mechanism of oxide formation is still unclear (Vracar et al. 1998), and it has been widely accepted that the $\mathrm{OH}^{-}$ion is initially adsorbed on the Pd (Reaction 1), which
Fig. 2 Transmission Electron Microscopy of MN a nanoclusters, $\mathbf{b}$ nanorods and c, d nanocrystalline PdNicoated $\mathrm{MN}$
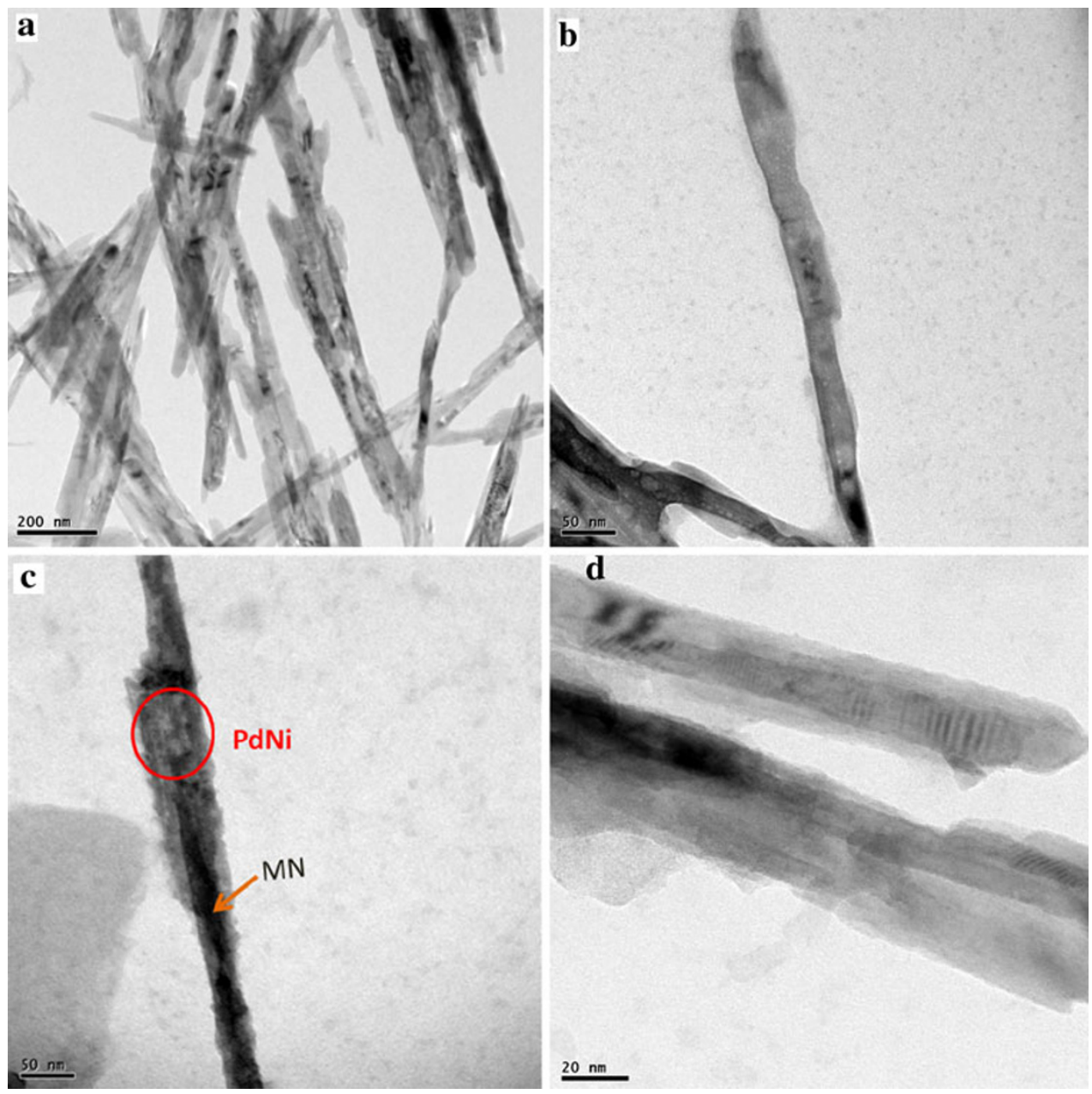
Fig. 3 Energy dispersive X-ray spectroscopy of nanocrystalline PdNi-coated MN
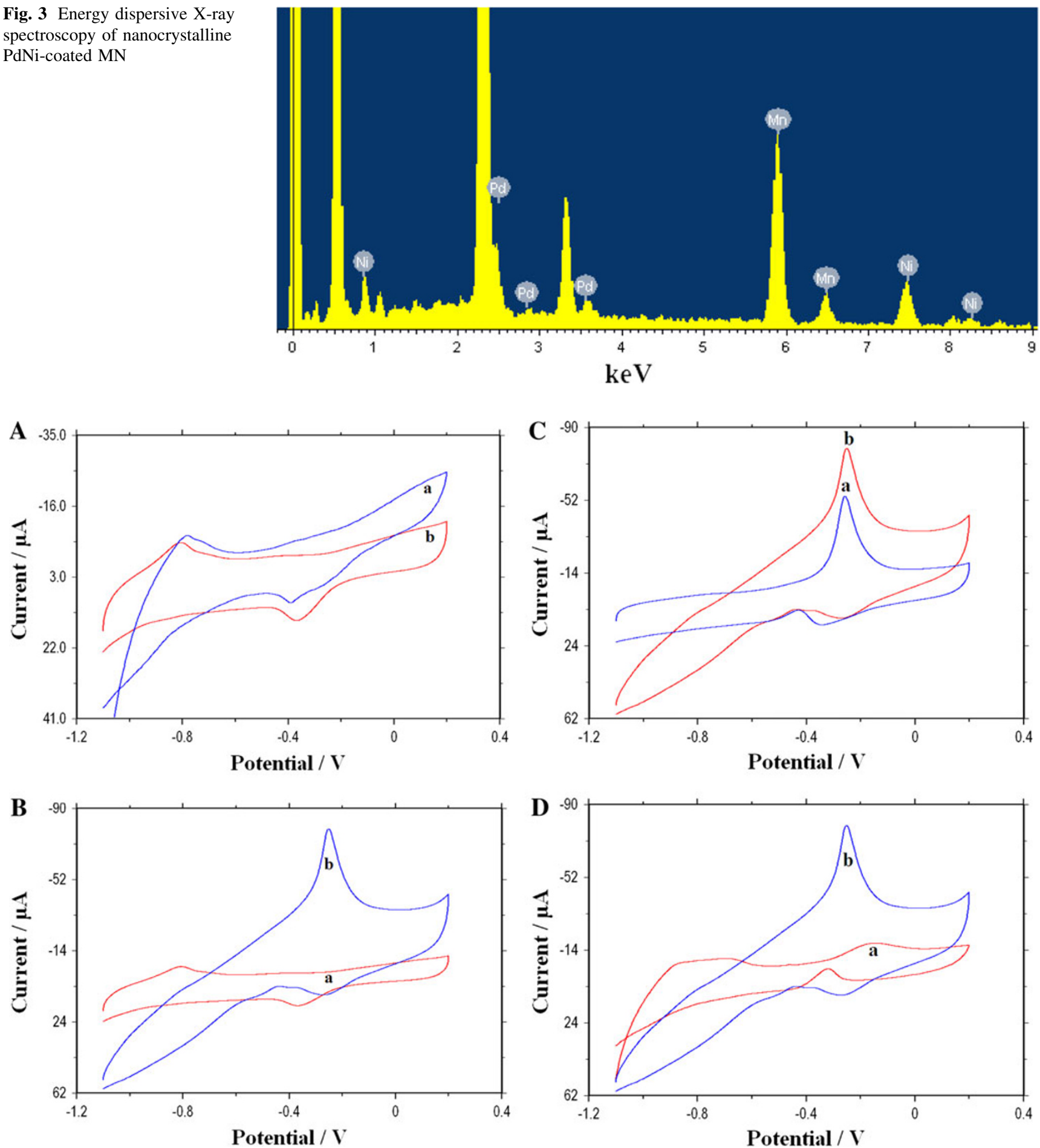

Fig. 4 Cyclic voltammogrames of GC modified $\mathrm{A} a \mathrm{Pd} / \mathrm{MN} b \mathrm{PdNi} /$ $\mathrm{MN}$ in $1 \mathrm{M} \mathrm{KOH}$; B PdNi in (a) $1 \mathrm{M} \mathrm{KOH}(b) 1 \mathrm{M} \mathrm{KOH} / 1 \mathrm{M}$ $\mathrm{CH}_{3} \mathrm{OH} ; \mathbf{C}$ electrooxidation of Methanol $a \mathrm{Pd}$ and $b \mathrm{PdNi} / \mathrm{MN}$ and

can be transformed to oxides at higher potential and further it helps to oxidize the methanol during the reaction. Further, at $-0.365 \mathrm{~V}(\mathrm{PdNi})$ and $-0.39 \mathrm{~V}(\mathrm{Pd})$ during the cathodic sweep the Pd (II) is reduced to Pd. This is due to active oxygen supplied by the supporting $\mathrm{MN}$ material which

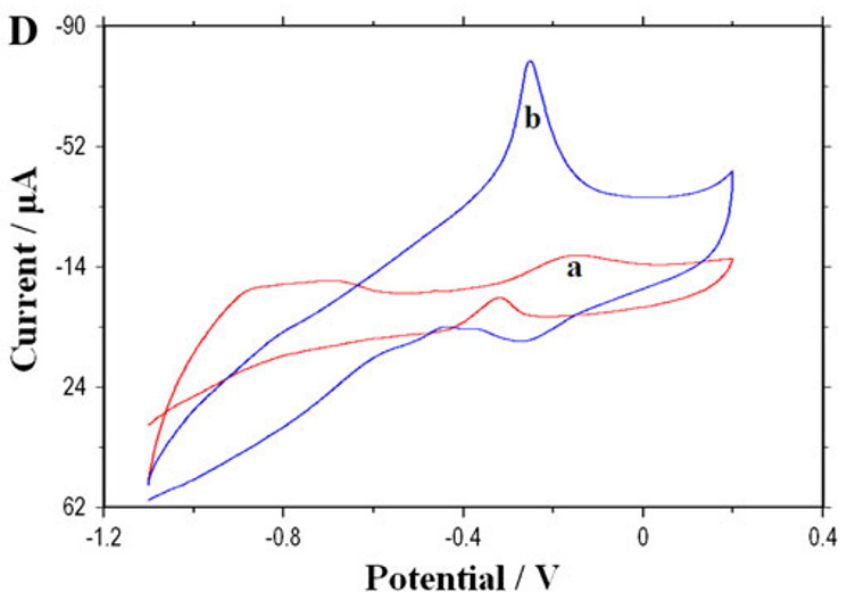

D electrooxidation of Methanol $\left(1 \mathrm{M} \mathrm{KOH} / 1 \mathrm{M} \mathrm{CH}_{3} \mathrm{OH}\right)$ in $a \mathrm{Pd}$ on fine graphite powder and $b \mathrm{PdNi} / \mathrm{MN}$

would facilitate the reduction. Figure $4 \mathrm{Ba}, \mathrm{b}$ shows the cyclic voltammograms of the absence and the presence of methanol in the PdNi/MN catalyst modified electrode, which confirms the oxidation peak, to be due to the methanol oxidation by the catalyst. 
The methanol oxidation reaction starts around $-0.8 \mathrm{~V}$ and a vertex potential at $-0.27 \mathrm{~V}$ is observed during the forward scan and second oxidation of surface chemisorbed intermediates at $-0.418 \mathrm{~V}$. The hydrogen adsorption region $-0.81 \mathrm{~V}$ is significantly suppressed in the methanol electrooxidation in the alkaline solution, due to the dissociative adsorption of methanol molecules on the catalyst. The oxidation was clearly shown after $-0.81 \mathrm{~V}$, which may be attributed to the effective participation of $\mathrm{OH}^{-}$ion. It is generally believed that these $\mathrm{Ni}$ species are oxophilic like $\mathrm{Ru}$, and have the capacity to generate $\mathrm{OH}_{\text {ads }}$ at a lower potential, to facilitate the oxidation of the intermediate products, thus enhancing the catalytic activity of Pd catalyst (Bambagioni et al. 2009; Manoharan and Prabhuram 2001).

The cyclic voltammograms of $\mathrm{Pd} / \mathrm{MN}$ and $\mathrm{PdNi} / \mathrm{MN}$ (5\% of Pd; Fig. 4Ca, b) in $1 \mathrm{M} \mathrm{KOH} / 1 \mathrm{M} \mathrm{CH}_{3} \mathrm{OH}$ solution has been compared, and it indicates that the PdNi/MN exhibits a higher electrocatalytic activity with enhanced current response compared to $\mathrm{Pd} / \mathrm{MN}$. The vertex potential is almost the same for both $\mathrm{Pd}$ as well as PdNi-coated MN systems (Fig. 4Ca, b). The $\mathrm{PdNi} / \mathrm{MN}$ with $\mathrm{Pd} / \mathrm{C}$ was studied for the electrocatalytic behavior in MOR. The vertex potential $\mathrm{Ep}=-0.27 \mathrm{~V}$ for $\mathrm{PdNi} / \mathrm{MN}$ is negatively shifted by $\sim 150 \mathrm{mV}$ compared to Pd/C (Fig. 4Da, b). This clearly indicates that the presence of $\mathrm{Ni}$ does not alter the peak potential, however MN readily supply active oxygen to the catalyst, which subsequently oxidize the ad/absorbed poisonous intermediates and extract $\mathrm{OH}^{-}$from the solution and reconstruct the surface. Hence, the vertex oxidation potential is shifted to a lower region compared to that of $\mathrm{Pd} / \mathrm{C}$. Another interesting characteristic result that was observed is that the 11th cycle exhibits a higher current response compared to the first cycle, and one can infer that the $\mathrm{PdNi} / \mathrm{MN}$ by this method towards MOR is closely related to the potential cycling number, and it seems that more potential sweeping cycles favor the process of MOR.

Figure 5A, B shows the cyclic voltammograms of MOR on the $\mathrm{PdNi} / \mathrm{MN}$ on $\mathrm{GC}$ electrode in $1 \mathrm{M}$ methanol solution containing various concentration of $\mathrm{KOH}$ ranging from $1-$ $9 \mathrm{M}$. The peak potential was continuously shifted negative with increased peak current response which was observed with an increase in $\mathrm{KOH}$ concentration. At high $\mathrm{pH}$, methanol oxidation rate increases appreciably, which is due to the change of the reactant from $\mathrm{CH}_{3} \mathrm{OH}$ to $\mathrm{CH}_{3} \mathrm{O}^{-}$and of adsorbed intermediate from $\equiv \mathrm{C}-\mathrm{OH}$ to $\equiv \mathrm{C}-\mathrm{O}^{-}$. The states of oxidation of the Pd surface also change at alkaline $\mathrm{pH}$ and the anionic adsorption is diminished. In all these concentrations the featured peaks were observed both as forward and backward oxidation peaks, which indicate that the prepared nanocomposite-coated GC electrode was smooth like the noble metals (Manoharan and Prabhuram 2001). Figure 5B shows the peak current was increased with increasing concentration up to $9 \mathrm{M} \mathrm{KOH}$. The highest current was observed at $6 \mathrm{M} \mathrm{KOH} / 9 \mathrm{M} \quad \mathrm{CH}_{3} \mathrm{OH}$ (Fig. 5Bb). The observed backward oxidation peak current density was very less due to the presence of manganese oxide as a support material in PdNi. Here $\mathrm{MN}$ as a support material will supply the oxygen to the catalyst and $\mathrm{Ni}$ will adsorb the $\mathrm{OH}^{-}$to oxidize the poisonous intermediates effectively. The possible reaction mechanism of electrooxidation of methanol at $\mathrm{PdNi} / \mathrm{MN}$ is follows.

$$
\begin{aligned}
& \mathrm{Pd}+\mathrm{H}_{2} \mathrm{O} \rightarrow \mathrm{Pd}(\mathrm{OH})_{\mathrm{ads}}+\mathrm{H}^{+}+\mathrm{e}^{-} \\
& \mathrm{Pd}+\left(\mathrm{CH}_{3} \mathrm{OH}\right) \rightarrow \mathrm{Pd}\left(\mathrm{CH}_{3} \mathrm{OH}\right)_{\mathrm{ads}} \\
& \mathrm{Pd}+\left(\mathrm{CH}_{3} \mathrm{OH}\right)_{\mathrm{ads}} \rightarrow \mathrm{Pd}(\mathrm{COH}) \\
& \mathrm{Pd}(\mathrm{COH})+\mathrm{H}_{2} \mathrm{O} \rightarrow \mathrm{Pd}(\mathrm{HCOOH})_{\mathrm{ads}}+\mathrm{H}^{+}+\mathrm{e}^{-} \\
& \mathrm{Pd}(\mathrm{HCOOH})_{\mathrm{ads}} \rightarrow \mathrm{Pd}(\mathrm{CO})_{\mathrm{ads}}+\mathrm{H}_{2} \mathrm{O} \\
& \mathrm{Pd}(\mathrm{CO})_{\mathrm{ads}}+\mathrm{Pd}(\mathrm{OH})_{\mathrm{ads}} \rightarrow 2 \mathrm{Pd}+\mathrm{CO}_{2} \uparrow+\mathrm{H}_{2} \mathrm{O} \\
& \mathrm{Ni}+\mathrm{H}_{2} \mathrm{O} \rightarrow \mathrm{Ni}(\mathrm{OH})_{\mathrm{ads}}+\mathrm{H}^{+}+\mathrm{e}^{-} \\
& \mathrm{Pd}(\mathrm{CO})_{\mathrm{ads}}+\mathrm{Ni}(\mathrm{OH})_{\mathrm{ads}} \rightarrow \mathrm{Pd}+\mathrm{Ni}+\mathrm{CO}_{2} \uparrow+\mathrm{H}_{2} \mathrm{O}
\end{aligned}
$$
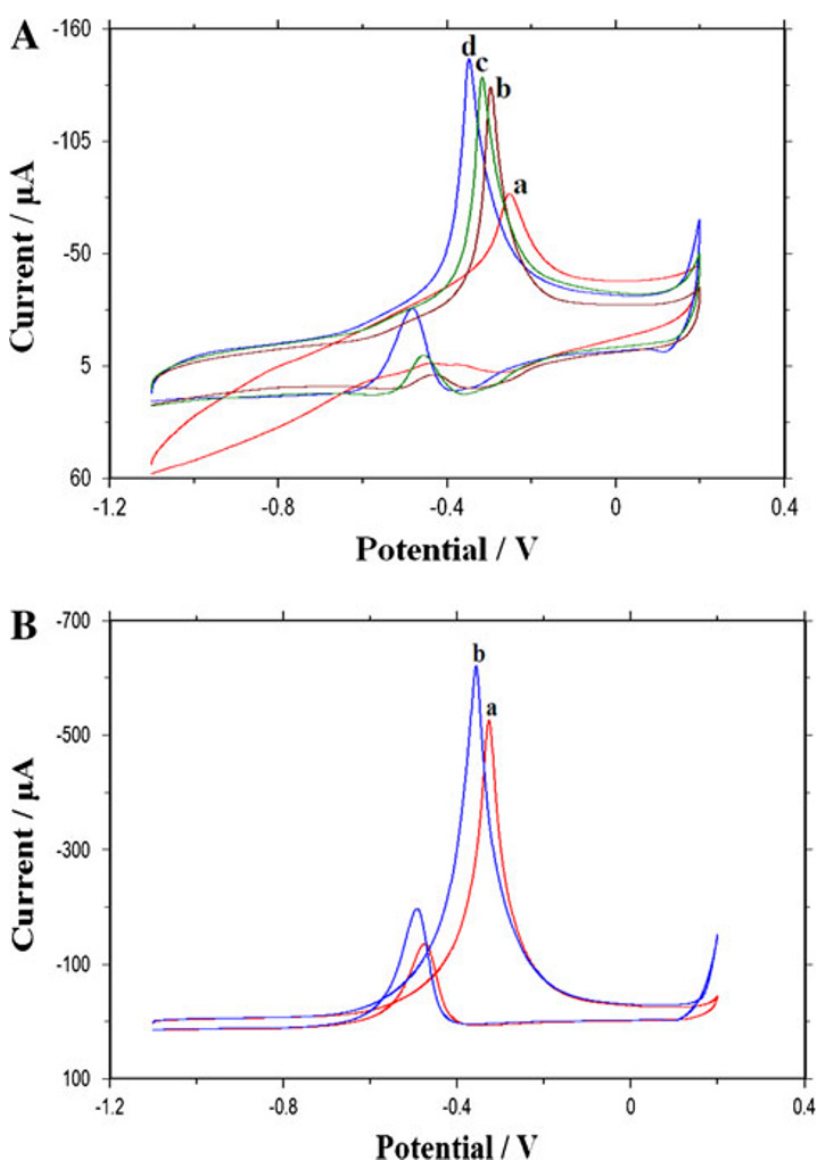

Fig. 5 A Cyclic voltammogrames of electrooxidation of Methanol at $\mathrm{PdNi} / \mathrm{MN}$ in $1 \mathrm{M} \mathrm{CH}_{3} \mathrm{OH}$ with $a 1 \mathrm{M} b 3 \mathrm{M} c 6 \mathrm{M}$ and $d 9 \mathrm{M} \mathrm{KOH}$; B $a 6 \mathrm{M} \mathrm{KOH} / 6 \mathrm{M} \mathrm{CH}_{3} \mathrm{OH}$ and $b 9 \mathrm{M} \mathrm{KOH} / 6 \mathrm{M} \mathrm{CH}_{3} \mathrm{OH}$. (Scan rate $50 \mathrm{mV} / \mathrm{s}$ ) 
In general, $\mathrm{Pd}(\mathrm{CO})_{\text {ads }}$ is treated as a poisonous intermediate which hinders the activity of $\mathrm{Pd}$, Initially $\mathrm{Pd}$ will adsorb the $\mathrm{OH}^{-}$, which further helps to degrade the poisonous intermediates (Reactions 1-6). In the presence of $\mathrm{Ni}$ as adatom to $\mathrm{Pd}$, and being an oxophilic nature, it readily forms $\mathrm{Ni}(\mathrm{OH})_{\text {ads }}$, which is supplied to the catalytic $\mathrm{Pd}$, thereby the electrocatalytic activity was improved and the availability of active $\mathrm{Pd}$ sites were increased (Reactions 7, 8). Hence, the electrocatalytic activity of $\mathrm{PdNi} / \mathrm{MN}$ was enhanced even in higher alkaline condition.

On increasing the Pd loading to $10 \mathrm{wt} \%$ on the $\mathrm{MN}$ material (Fig. 6Ab), the cyclic voltammogrames characteristics for $1 \mathrm{M} \mathrm{KOH} / 1 \mathrm{M} \mathrm{CH} \mathrm{CH}_{3} \mathrm{OH}$ remained same as those obtained for the $5 \mathrm{wt} \% \mathrm{Pd} / \mathrm{MN}$ (Fig. 6Aa) nanocomposite material except that a higher current output has
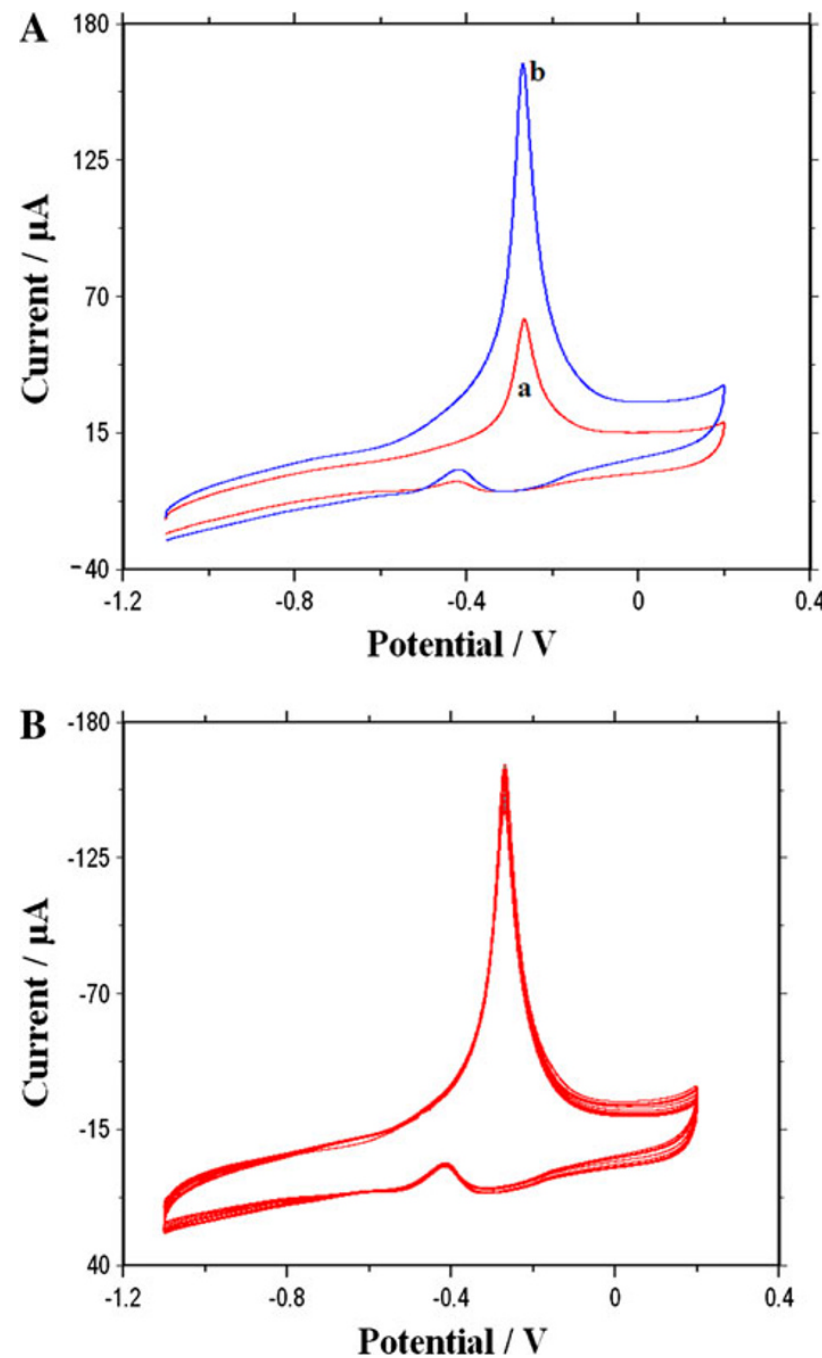

Fig. 6 A Cyclic voltammogrames of electrooxidation of $1 \mathrm{M} \mathrm{KOH} /$ $1 \mathrm{M} \mathrm{CH}_{3} \mathrm{OH}$ at $a 5 \mathrm{wt} \%$ and $b 10 \mathrm{wt} \% \mathrm{Pd}$ in $\mathrm{PdNi} / \mathrm{MN}$; B CVs of $1 \mathrm{M} \mathrm{KOH} / 1 \mathrm{M} \mathrm{CH}_{3} \mathrm{OH}$ at PdNi/MN scanned for 20 segments (Scan rate $50 \mathrm{mV} / \mathrm{s}$ ) been obtained. Fig 6B shows the cyclic voltammogrames of PdNi/MN nanocomposite for $1 \mathrm{M} \mathrm{KOH} / 1 \mathrm{M} \mathrm{CH}_{3} \mathrm{OH}$ electrooxidation during the first 20 segments. The degree of reduction in current is lower as the number of segment increases from 1 to 20 . The peak current remained almost constant. From these results, it is clear that the superior stability of the PdNi/MN electrode towards methanol electrooxidation over repetitive potential segment proves that the surface poisoning by the reaction intermediates does not affect the catalytic activity.

\section{Conclusion}

In the present work, nanocrystalline PdNi was coated on $\mathrm{MN}$ and was tested for its electrocatalytic oxidation of methanol. The experimental results show the prepared catalyst exhibits improved electrocatalytic activity towards methanol. The oxidation potential was shifted to a lower potential and the peak current was also increased. 5\% and $10 \% \mathrm{Pd}$ with $\mathrm{Ni}$ was tested for the electrooxidation of methanol. The relative backward oxidation current was shifted in the negative direction with increasing concentration. The maximum oxidation current was shown at $6 \mathrm{M}$ $\mathrm{KOH} / 9 \mathrm{M} \mathrm{CH}_{3} \mathrm{OH}$. The $\mathrm{MN}$ acts as a supportive material, which extracts the active oxygen from the electrolyte and oxidizes the intermediate.

Acknowledgments The authors thank the DST, India for provided the research facilities under DST nanomission project. Authors express gratitude to the authorities of Karunya University, Coimbatore, and Sona College of Technology, Salem, for their kind support.

Open Access This article is distributed under the terms of the Creative Commons Attribution License which permits any use, distribution and reproduction in any medium, provided the original author(s) and source are credited.

\section{Reference}

Bambagioni V, Bianchini C, Filippi J, Oberhauser W, Marchionni A, Vizza F, Psaro R, Sordelli L, Foresti ML, Innocenti M (2009) Ethanol oxidation on electrocatalysts obtained by spontaneous deposition of Palladium onto nickel-zinc material. ChemSusChem 2:99-112

Bianchini C, Shen PK (2009) Palladium-based electrocatalysts for alcohol oxidation in half cells and in direct alcohol fuel cells. Chem Rev 109:4183-4206

Conway BE (1981) In: Trasatti S (ed) Electrodes of conductive metallic oxides: part A. Chap 9 Elsevier, Amsterdam

Goodenough JB, Hamnett A, Kennedy BJ, Weeks SA (1987) XPS investigation of platinized carbon electrodes for the direct methanol air fuel cell. Electrochim Acta 32:1233-1238

Goodenough JB, Hamnett A, Kennedy BJ, Manoharan R, Weeks SA (1988) Methanol oxidation on unsupported and carbon supported $\mathrm{Pt}+\mathrm{Ru}$ anodes. J Electroanal Chem 240:133-145 
Leger JM (2001) Mechanistic aspects of methanol oxidation on platinum-based electrocatalysts. J Appl Electrochem 31:767-771

Liu Z, Zhang X, Hong L (2009) Physical and electrochemical characterizations of nanostructured $\mathrm{Pd} / \mathrm{C}$ and $\mathrm{PdNi} / \mathrm{C}$ catalysts for methanol oxidation. Eelctrochem Commun 11:925-928

Maiyalagan T, Scott K (2010) Performance of carbon nanofiber supported $\mathrm{Pd}-\mathrm{Ni}$ catalysts for electro-oxidation of ethanol in alkaline medium. J Power Sources 195:5246-5251

Manoharan R, Prabhuram J (2001) Possibility of prevention of formation of poisoning species on direct methanol fuel cell anodes. J Power Sources 96:220-225

Miao F, Tao B, Sun L, Liu T, You J, Wang L, Chu PK (2010) Preparation and characterization of novel nickel-palladium electrodes supported by silicon microchannel plates for direct methanol fuel cells. J Power Source 195:146-150

Qi Z, Geng H, Wang X, Zhao C, Ji H, Zhang C, Hu J, Zhang Z (2011) Novel nanocrystalline PdNi alloy catalyst for methanol and ethanol electro-oxidation in alkaline media. J Power Sources 196:5823-5828

Shibata M, Motoo S (1986) Electrocatalysis by ad-atoms: part XX. Rate-determining step in methanol oxidation enhanced by oxygen-adsorbing ad-atoms. J Electroanal Chem 209:151-158
Singh RN, Singh A, Anindita (2009) Electrocatalytic activity of binary and ternary composite films of Pd, MWCNT and Ni, Part II: methanol electrooxidation in $1 \mathrm{M} \mathrm{KOH}$ Int. J Hydrogen Energy 34:2052-2057

Suresh kumar K, Haridoss P, Seshadri SK (2008) Synthesis and characterization of electrodeposited Ni-Pd alloy electrodes for methanol oxidation. Surf Coat Technol 202:1764-1770

Vracar LJ, Burojevic S, Krstajic N (1998) The surface processes at $\mathrm{Pd}-\mathrm{Ni}$ alloy in acid and alkaline solutions. Int $\mathrm{J}$ Hydrogen Energy 23:1157-1164

Wei Y-C, Liu C-W, Kang W-D, Lai C-M, Tsai L-D, Wang K-W (2011) Electro-catalytic activity enhancement of Pd-Ni electrocatalysts for ethanol electrooxidation in alkaline medium: the promotional effect of $\mathrm{CeO}_{2}$ addition. $\mathrm{J}$ Electroanal Chem 660:64-70

$\mathrm{Xu} \mathrm{C}$, Tian Z, Shen P, Jiang SP (2008) Oxide $\left(\mathrm{CeO}_{2}, \mathrm{NiO}, \mathrm{Co}_{3} \mathrm{O}_{4}\right.$ and $\mathrm{Mn}_{3} \mathrm{O}_{4}$ )-promoted $\mathrm{Pd} / \mathrm{C}$ electrocatalysts for alcohol electrooxidation in alkaline media. Electrochim Acta 53:2610-2618

Zhao Y, Jang X, Tian J, Wang F, Zhan L (2010) Methanol electrooxidation on $\mathrm{Ni} @ \mathrm{Pd}$ core-shell nanoparticles supported on multi-walled carbon nanotubes in alkaline media. Int J Hydrogen Energy 35:3249-3257 